\title{
ASSESSING THE IMPORTANCE OF PAST HUMAN BEHAVIOR IN DENDROARCHAEOLOGICAL RESEARCH: EXAMPLES FROM RANGE CREEK CANYON, UTAH, U.S.A.
}

\author{
RONALD H. TOWNER ${ }^{1 *}$, MATTHEW W. SALZER ${ }^{1}$, JAMES A. PARKS ${ }^{1}$, and K. RENEE BARLOW ${ }^{2}$ \\ ${ }^{1}$ Laboratory of Tree-Ring Research, University of Arizona, Tucson, Arizona, 85721, USA \\ ${ }^{2}$ College of Eastern Utah, Price, Utah, 84501, USA
}

\begin{abstract}
Dendroarchaeological samples can contain three kinds of information: chronological, behavioral, and environmental. The decisions of past people regarding species selection, beam size, procurement and modification techniques, deadwood use, and stockpiling are the most critical factors influencing an archaeological date distribution. Using dendrochronological samples from prehistoric and historic period sites in the same area of eastern Utah, this paper examines past human behavior as the critical factor in dendroarchaeological date distributions.
\end{abstract}

Keywords: Dendroarchaeology, past human behavior, species selection, beam selection, Range Creek Canyon, Utah, Fremont Culture.

\section{INTRODUCTION}

Dendroarchaeology is the use of dendrochronological materials, wood and charcoal, to address questions of archaeological, anthropological, and historical interest. Dendroarchaeological samples contain three kinds of information: chronological, behavioral, and environmental (Dean 1996a; Ahlstrom 1997; Towner 2002), all of which are interconnected. This paper examines one factor in dendroarchaeology - the wood-use behaviors of past people and the resultant impacts on dendroarchaeological dating quantity and quality. The decisions (behavior) of past people regarding wood use determine the quantity and quality of chronological and environmental information that can be derived from archaeological tree-ring samples. In this particular case, we examine the past behaviors of the inhabitants of the Range Creek area of eastern Utah, U.S.A., by comparing prehistoric Fremont and historical period AngloAmerican wood-use practices (Figure 1).

Dean (1996a, 1996b) has provided an excellent theoretical basis for understanding how and why past human behavior is the critical factor in

\footnotetext{
*Corresponding author: rtowner@1trr.arizona.edu
}

dendroarchaeology. He compares Navajo and Puebloan wood use practices and their effects on dating quantity, quality, and date distributions. The Puebloan construction of masonry rooms and use of stone axes limited the number of deadwood elements, promoted stockpiling of timbers for communal projects, necessitated the selection of long straight timbers to span rooms, and favored species with those attributes. In contrast, the Navajo construction of a multiplicity of structures using metal axes resulted in the use of many tree species, irregular timber size and shape, abundant deadwood use, and frequent structure repair and remodeling. These differences in wood use behaviors create the dendroarchaeological records that are available today and thus impact our ability to conduct dendroarchaeological research.

Ahlstrom (1985, 1997) demonstrates how construction techniques, architectural type, and abandonment processes have influenced dating quality and quantity for much of the prehistoric northern Southwest U.S. He used three large data sets to examine variation in the prehistoric archaeological tree-ring record across the Colorado Plateau and identified six major factors that impact regional date distributions (Ahlstrom 


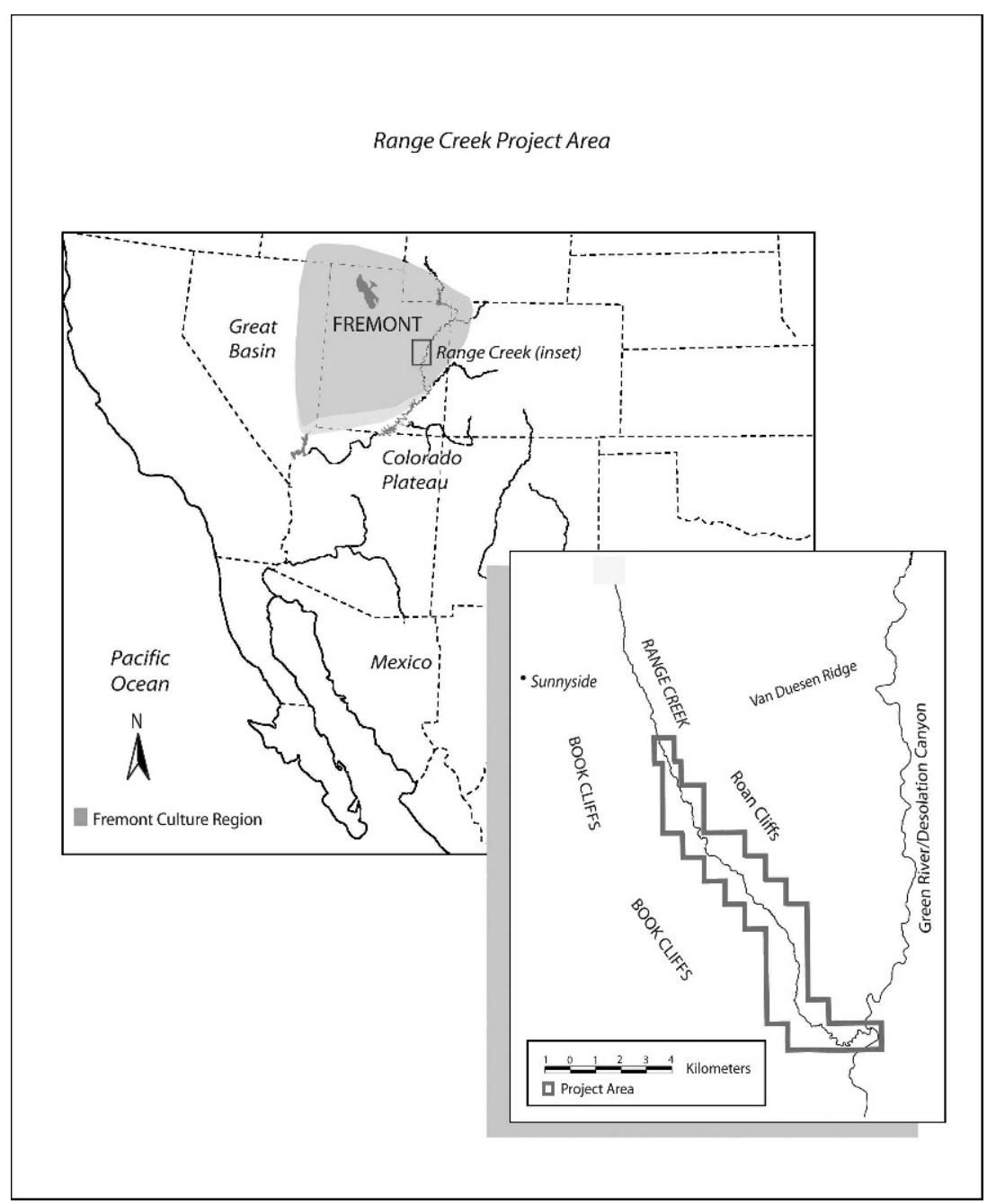

Figure 1. Range Creek, Utah, area.

1997:322-323). Of these, the three factors most germane to the Range Creek data sets are: (1) the wood procurement practices of the site builders; most importantly, did the prehistoric residents have access to and use dendrochronologically useful species (i.e. Douglas-fir, pinyon, ponderosa pine, juniper), (2) the wood-use practices of the site occupants; did they use freshly cut or recycled timbers, deadwood, or stockpiled beams in construction, and (3) whether a site/structure was built in an open or sheltered environment; an important factor in the preservation of dendroarchaeological samples. We add a fourth factor, technology, when comparing prehistoric and historic samples; the use of metal axes and draft animals may have influenced tree selection in Range Creek during the historical period, but we cannot quantify technology at this time. All these factors are important in the interpretation of the Range Creek dendroarchaeological record.

Assigning accurate dates to archaeological samples requires the matching of ring-width patterns in the archaeological wood against a previously constructed reference chronology for the region. In general, the higher the quality of the reference chronology, the better suited it is for dating purposes. Chronology quality is measured by various statistics (i.e. mean series intercorrela- 
tion, signal to noise ratio, signal strength, etc., see Fritts 1976). However, in dendroarchaeological dating many archaeologists and others often assume that more samples and a stronger chronology - as measured by dendroarchaeological sample depth-will result in a higher success rate for dating archaeological specimens. In areas with few developed chronologies this may be partially true, but as the examples below illustrate, past human behavior is the critical factor in the success of archaeological tree-ring dating.

The purpose of this paper is to examine the dating quantity and quality of two different collections from the same area of eastern Utah (Figure 1): samples from historic period AngloAmerican homestead structures and samples from archaeological structures built by the prehistoric Fremont culture. We compare the collections graphically and numerically, both internally and between collections. Initially, however, we examine the variability of our master chronology for each time period.

\section{PROJECT SETTING}

During the past three years, we have developed living tree chronologies and dated historic and prehistoric structures in the Range Creek area of eastern Utah (Figure 1). On the northern Colorado Plateau adjacent to the Rocky Mountains, Range Creek is one of the deep canyons of the Green River drainage, with a confluence just below Desolation Canyon. The area is characterized by steep Vshaped canyons, narrow flat floodplains, and highelevation plateaus. Range Creek elevation ranges from 4,230 ft. (1,290 m) a.s.l. at its confluence with the Green River to $10,117 \mathrm{ft}$. (3,084 m) at its headBruin Point. The terrain is rugged and steep, heavily vegetated, and the catchment area supports a wide array of indigenous flora and fauna. Ecological zones range from mixed subalpine and riparian taxa at elevations above $8,000 \mathrm{ft}$. $(2,440 \mathrm{~m})$ in the upper canyon, to hot desert shrub communities in the lower canyon at 4,250 ft. $(1,295 \mathrm{~m})$. The climate is typically continental with cold snowy winters and hot summers until seasonal rains occur in July and August. No long-term precipitation data are available yet for the canyon itself, but precipitation in nearby Price, Green River, and Nutter's Ranch averages only about $10-12 \mathrm{in}$. $(25-30 \mathrm{~cm})$ per annum, with a relatively even distribution throughout the year. The predominant dendrochronologically useful tree species are Douglas-fir (Pseudotsuga menziesii) and pinyon (Pinus edulis); other conifers, such as juniper (Juniperus spp.), have yet to be crossdated.

\section{Previous Research}

The first dendrochronological research in the area was conducted by Edmund Schulman. In 1946, he expanded his interest in old-age conifers and the Colorado River Basin into northeastern Utah (Schulman 1948). Schulman collected living tree samples from Nine Mile Canyon, approximately 50 air miles ( $c a .80 \mathrm{~km}$ ) north of Range Creek in 1947 and 1948 and actively sought the collaboration of archaeologists to extend his chronology using archaeological samples. Using samples from several living tree and archaeological sites, he extended his chronology back to A.D. 397 (Schulman 1948).

After Schulman's efforts, dendroarchaeology in northeastern Utah languished for almost four decades. In 1984, the U.S. National Park Service's Midwest Archaeological Center conducted excavations in a small rockshelter (42 UN 1103) in Dinosaur National Monument $90 \mathrm{mi}$. (145 km) northeast of Range Creek. The eight samples submitted, all pinyon, yielded seven dates with ring series ranging from $1291 \mathrm{p}-1682 \mathrm{vv}$ (see Robinson et al. 1974 for an explanation of archaeological date symbols used by the Laboratory of Tree-Ring Research [LTRR]). Finally, in 1987, Abajo Archaeology submitted 12 samples, of which four produced dates with ring series ranging from A.D. $1046 p$ to $1156+r$ from a Fremont pithouse (Site 42 Em 2095) approximately 40 air miles ( $c a .64 \mathrm{~km})$ west-southwest of Range Creek. It was not until the initiation of the Range Creek project that additional dendroarchaeological research was conducted in the area.

\section{The Range Creek Project}

A total of 266 samples were collected from archaeological contexts (primarily wood beams from 


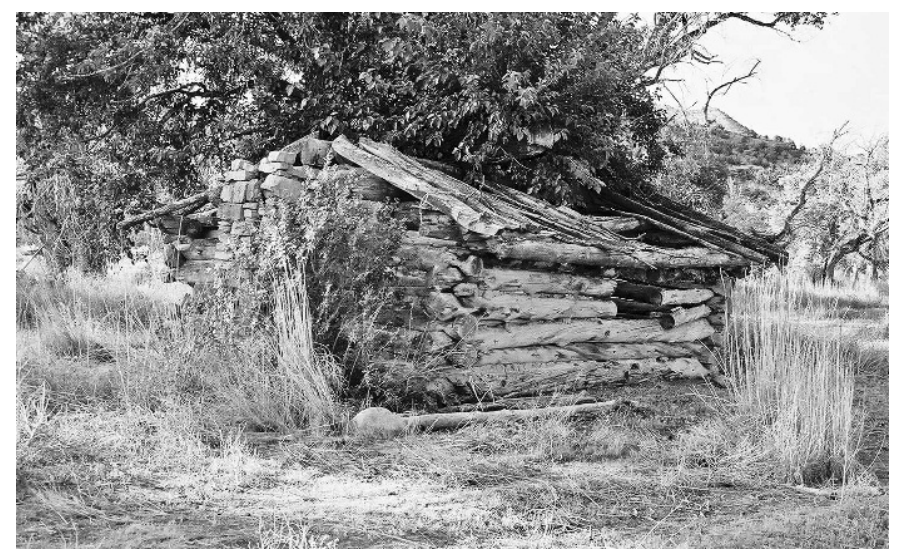

Figure 2. The Nutter Cabin.

structures) during this project. The project is divided into two components. In the first component we collected 69 samples from historical period AngloAmerican homestead structures; in the second we collected 197 samples from prehistoric Fremont structures. The samples were collected using specially adapted drill bits that produce $3 / 8^{\prime \prime}(9.5 \mathrm{~mm})$ diameter cores. All samples were crossdated against the Harmon Canyon master skeleton plot developed by Chris Baisan in 2006 using the Douglass method of skeleton plotting (Stokes and Smiley 1968).

The 69 historic period samples were derived from seven structures - two log cabins, two fences, a dugout, a corral, and a hay derrick. The homestead cabins are large rectangular structures $(5-7 \mathrm{~m}$ on a side and 2-3 $\mathrm{m}$ high) composed of horizontal notched-log timber walls with gabled roofs of secondary beams supported by large primary beams (Figure 2). Of the 69 historic period samples collected, one was a duplicate, the same tree used for two different beams, which reduces the total sample size to 68 trees. These samples yielded 43 dates, including 33 cutting or near cutting dates. This dating success rate of $63 \%$ is nearly twice the long-term LTRR dendroarchaeological rate of about $35 \%$. Historic period dated rings span the 1649-1895 period.

The 197 prehistoric samples were derived from 51 sites, all Fremont-era structures. Based on archaeological evidence, these were most likely constructed between A.D. 800 and 1300. Most samples are from small granaries (1-2 m diameter and $1.5 \mathrm{~m}$ high) that were used to store maize and other foodstuffs. Granaries (Figure 3) are commonly located on ledges and in shallow alcoves in the canyon walls of Range Creek and its tributaries, usually between 5 and $50 \mathrm{~m}$ above the canyon floor. These granaries have been interpreted as a means of protecting food from enemies (Barlow 2004). None of the prehistoric Fremont-era samples were obtained from habitation structures. Granary wooden elements include roof beams that were covered with mud and rocks to seal the chamber; prehistoric elements also include vertical and horizontal wall elements, parts of roof-hatch collars, and some timbers that were used as ladders or handholds to access the granaries. Some granaries were built atop wooden platforms that provided samples as well.

The 197 samples collected from Fremont granaries yielded 19 dates, including four cutting and near cutting dates; this dating success rate of 8 percent is substantially below the long-term average of the LTRR. The prehistoric dated rings span the A.D. 609-1126 period. An important question, therefore, is why there is such a difference in dating success. We evaluate if it is due to differences in quality in the tree-ring reference chronology at different times or if it is a result of past human behavior.

\section{EVALUATING THE MASTER CHRONOLOGY}

If differential dating success is a result of differences in the master chronology at different 


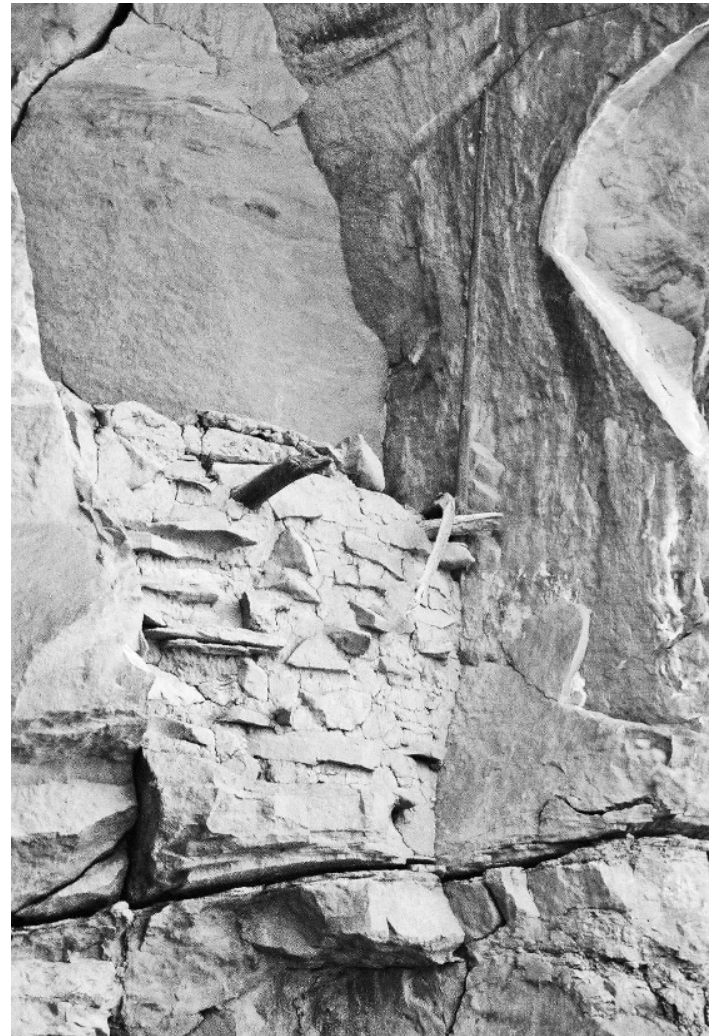

Figure 3. Fremont Culture granary, Site 42 Em 3048. time periods, such differences should be evident in an evaluation of the chronology. The reference chronology for dating and comparative purposes is a long, independently developed master chronology from nearby Harmon Canyon, and that chronology is evaluated below.

The simplest method of comparing the historic and prehistoric periods is by examining the master skeleton plot for each. Figure 4 shows the A.D. $1750-1870$ and $820-940$ portions of the Harmon Canyon master skeleton plot. These equal-length periods were chosen simply because they encompass the majority of the dated historical samples and one-third of the dated prehistoric samples. The entire plot was developed by a single analyst (C. Baisan) from living trees and remnant wood, so inter-analyst differences in plotting techniques are not a factor. Also, because this chronology was developed using only live-tree cores and remnant wood, it is completely independent of the archaeological samples.

The 120-year 820-940 period contains 52 "marker rings" (those noted on the plot as smaller than surrounding rings) and 10 " $\mathrm{B}$ " (big) rings; 16 rings received values greater than 5; and no extremely narrow $(>9)$ rings were noted. The A.D. $1750-1870$ period contains slightly fewer (n $=47)$ marker rings and fewer $(n=4)$ B rings, but slightly more $(\mathrm{n}=18)$ marker rings with values

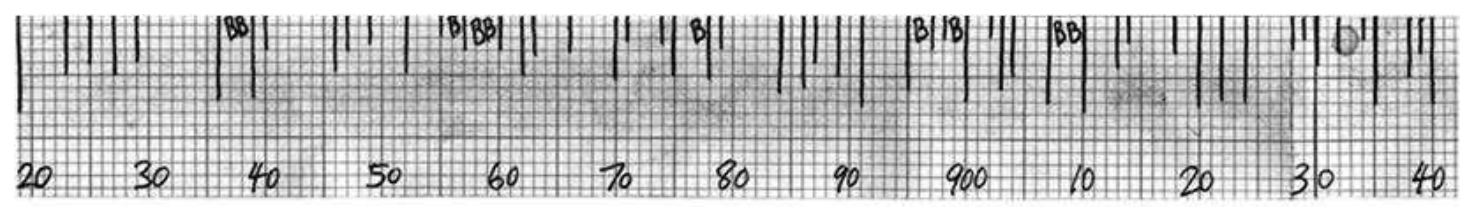

$A D$ 820-940: 52 rings with value, 10 " $B$ " rings, 16 rings value $>5$

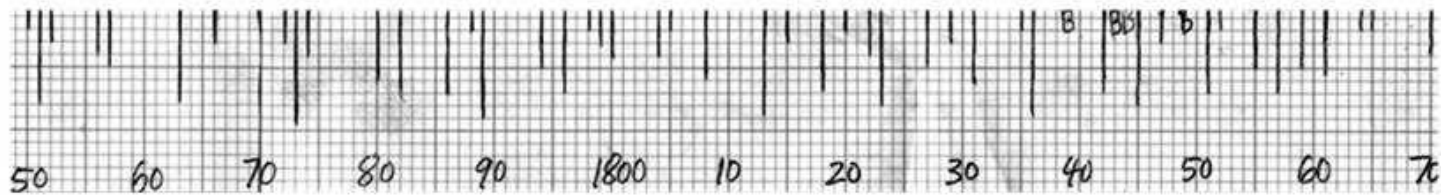

\section{$A D$ 1750-1870: 47 rings with value, 4 " $B$ " rings, 18 rings value $>5$}

Figure 4. Comparison of prehistoric and historic period skeleton plot segments of the Harmon Canyon master chronology. 
Table 1. Descriptive ring-width index statistics of selected time periods.

\begin{tabular}{lcc}
\hline & $820-940$ & $1750-1870$ \\
\hline $\mathrm{N}$ & 121 & 121 \\
Mean & 1.11 & 0.96 \\
Median & 1.11 & 0.92 \\
Stdev & 0.37 & 0.37 \\
Var & 0.14 & 0.14 \\
Min & 0.26 & 0.30 \\
Max & 2.22 & 1.95 \\
\hline
\end{tabular}

greater than 5 on the graphic scale; no extremely narrow $(>9)$ rings were identified. None of these differences is sizable, and graphically only the greater frequency of big rings in the A.D. 820-940 period might aid in crossdating. Thus, from a graphical crossdating perspective, the period variability is very similar.

Quantitative techniques were used to evaluate the two periods as well. As part of developing a precipitation reconstruction for the area, each ring in the Harmon Canyon chronology was measured to the nearest $0.001 \mathrm{~mm}$. Table 1 shows the descriptive statistics of the measured ring-width index values of each period of interest. There is little difference in the descriptive statistics for each period. The A.D. 820-940 period shows a slightly higher mean and wider range between minimum and maximum values than the A.D. 1750-1870 period, but the standard deviations and variances are identical. Thus, the earlier period is slightly more variable, but not tremendously so.

A more informative way to evaluate the quality of the ring-width values in the periods is to plot the annual values and their standard deviations (Figure 5). The early portion of the A.D. $820-940$ period has a wider dispersion around the mean, particularly in the A.D. $840-880$ period. The high variance is certainly influenced by the low sample size $(n=5)$ in the pre- 880 period. It may therefore influence dating success of pre- 880 samples, but should have little or no effect after A.D. 900. Furthermore, the Harmon Canyon chronology crossdates very well against Schulman's (1948) Nine Mile Canyon chronology, even in the early periods. If the Harmon Canyon master is deficient in some way in the A.D. 800s, we would expect it to match poorly against the Nine
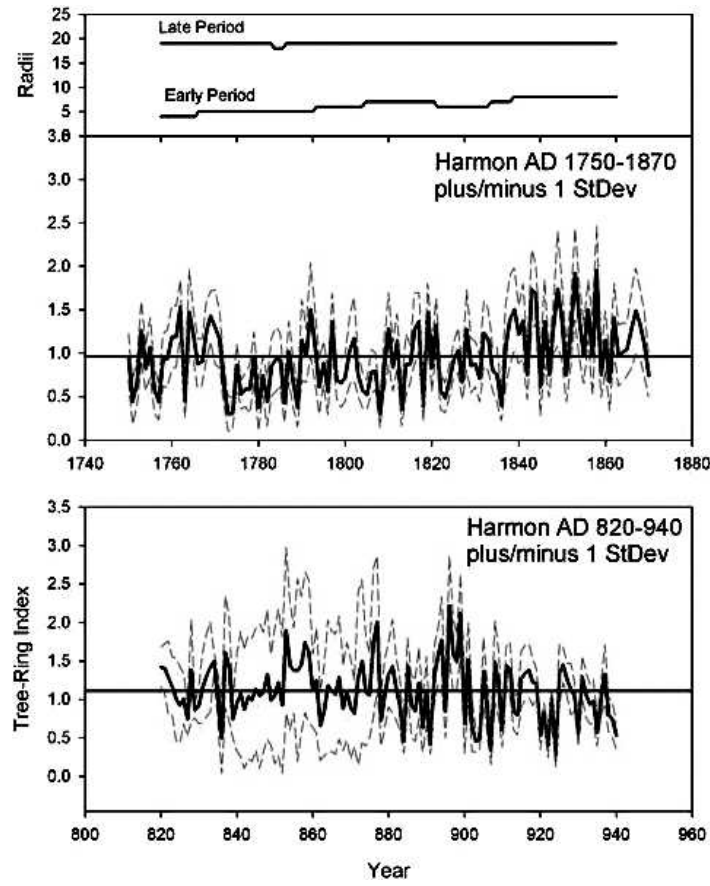

Figure 5. Harmon Canyon Douglas-fir index values and standard deviations for the A.D. 820-940 and 1750-1870 periods. Sample size for each period shown at top.

Mile Canyon chronology, but it matches quite well. In short, there appear to be no differences in the master chronology that would explain the different dating success rates of the Fremont-era and historic period dendroarchaeological samples.

\section{COMPARING THE DENDROARCHAEOLOGICAL COLLECTIONS}

If there are no important differences between the two periods of the master chronology, explanations for the different dating success rates must be sought in either the environmental or behavioral realms. An environmental explanation is unlikely because all of the sites are located in the same small area. All of the site occupants, Fremont and Anglo, had access to the same tree species and environmental zones. Although there have undoubtedly been environmental changes in Range Creek between A.D. 800 and 1900, such changes were probably not at a large enough scale to impact the distribution of datable trees - an 


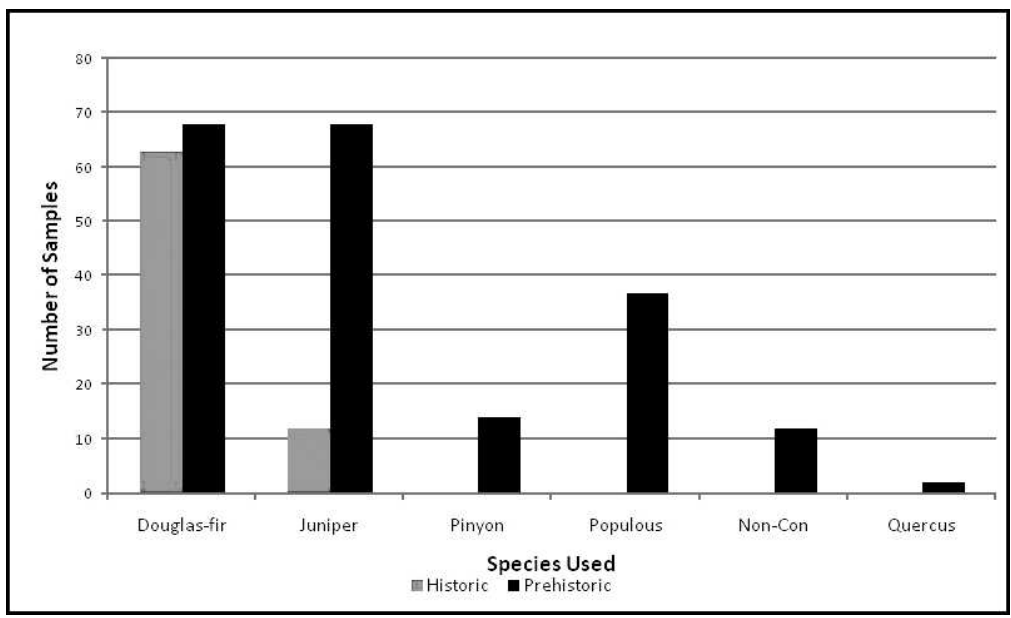

Figure 6. Tree species used by prehistoric and historic site occupants.

inference supported by the development of several independent master chronologies and precipitation reconstructions in eastern Utah (Schulman 1948; Gray et al. 2004; this project).

Humans can undoubtedly affect the quality of dendroarchaeological dates through wood-use practices, such as debarking and beam shaping, which often remove outer rings from samples. Such behaviors result in noncutting dates that predate timber harvesting by an unknown number of years (Dean 1996a). Under discussion here, however, is how past human behaviors affect the quantity of dendroarchaeological dating. When chronological and environmental factors are eliminated as causes for the different dating success rates, behavioral factors remain to be examined. Such factors include, but are not limited to, species selection, beam selection, and beam modification processes.

\section{Species Selection}

There is a dramatic difference in the species used in the historic and prehistoric structures in Range Creek (Figure 6). The historical population of the area used Douglas-fir almost exclusively in building construction. The Fremont builders of the prehistoric sites, on the other hand, exploited juniper (34.8\%), Douglas-fir (33.3\%), Populus spp. (cottonwood or aspen) (18.1\%), pinyon (6.9\%), non-coniferous (unidentified species) $(5.9 \%)$, and
Quercus spp. (oak) (1.0\%). The oaks, Populus, and non-coniferous species from this area typically do not contain enough distinctive rings or exhibit enough ring-width variability for crossdating. Archaeological samples of pinyon and juniper often yield dates in other parts of the Colorado Plateau. Indeed, two of our pinyon samples yielded dates, but species-specific chronologies have not been developed for the relevant time period in the Range Creek area. Thus, the primary reason for the lower dating success rate of prehistoric samples is simply that the Fremont used many more undatable species in construction than the Anglo homesteaders. Future development of an area-specific juniper chronology may increase the dating success rate but probably only marginally.

\section{Beam Size Comparisons}

Another important factor in dating success is the size of the individual sample. Although size does not always correlate with the number of rings on a sample, it can be a general guide to sample datability within a single species. Because pinyon samples occur only in prehistoric contexts, beam-size comparisons use only Douglas-fir samples. Comparing the radii of the prehistoric and historic period Douglas-fir samples yields interesting results.

When comparing the only dated species, Douglas-fir, it is clear that the homesteaders 


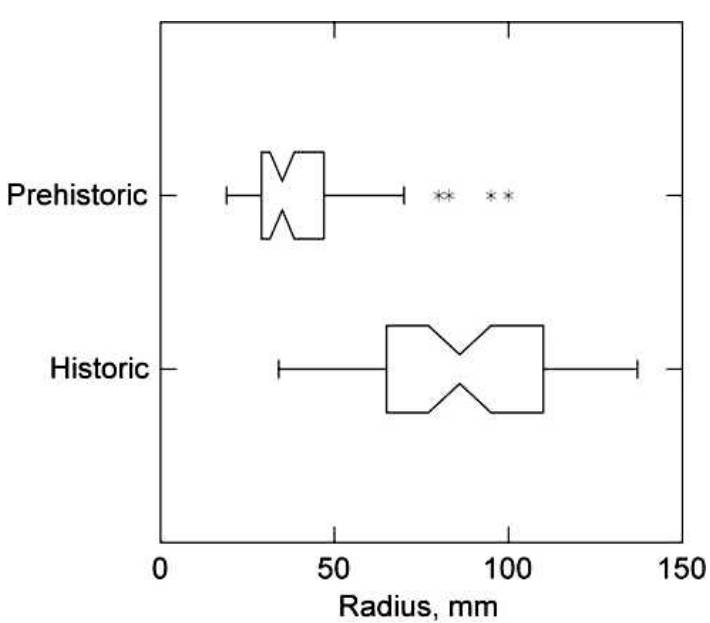

Figure 7. Box-and-whisker plot comparison of prehistoric and historic sample radii showing a significant difference in beam size $(t=11.087, \mathrm{df}=103.2, \mathrm{p}=0.000)$. Box ends indicate first and third quartiles, notches indicate confidence interval, whiskers show outliers, and asterisks illustrate extreme outliers.

selected larger beams. A two-sample t-test of the mean difference in the radii of the 63 historic period and 66 prehistoric period Douglas-fir samples yields a significant difference $(\mathrm{t}=$ 11.087, df $=103.2, p=0.000)$ in the size of the beams selected by each group. A notched box-andwhisker plot illustrates this difference (Figure 7). The much higher dating rate of the historic period timbers shows that the size of the timbers used in construction is an important variable in dating success. It is important to note, however, that some prehistoric beams are larger than some historic period beams; thus, size is not always the determining factor in datability.

Comparison of only the dated and undated prehistoric Douglas-fir samples yields different results (Figure 8). Dated samples are often larger than undated samples, but a two-sample t-test of mean size differences shows the difference is not statistically significant $(\mathrm{t}=2.290, \mathrm{df}=19.7, \mathrm{p}=$ 0.033). Thus, size alone cannot explain the low proportion of prehistoric dates.

\section{Ring Number Comparisons}

Because size does not always correlate with the number of rings on a specimen and because the number of rings and ring-width variability distin-

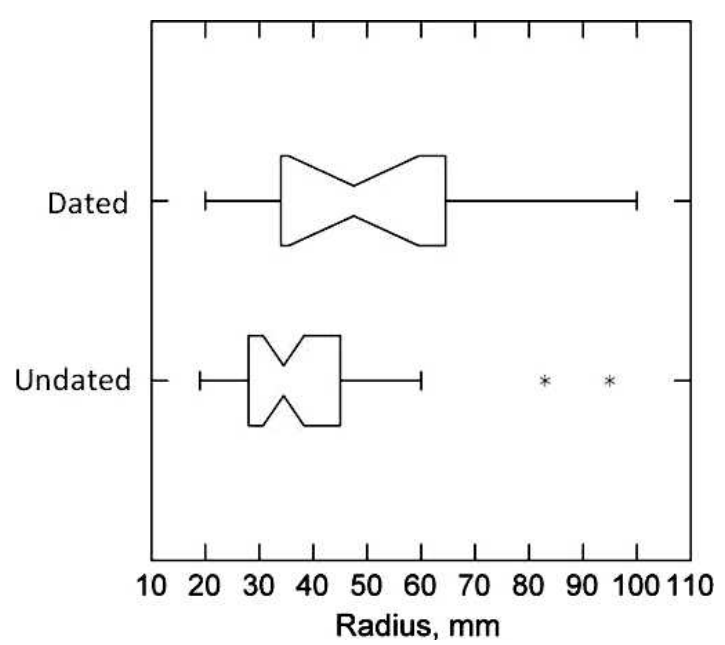

Figure 8. Comparison of dated and undated prehistoric Douglas-fir samples showing no significant size difference $(\mathrm{t}$ $=2.290, \mathrm{df}=19.7, \mathrm{p}=0.030$ ).

guish datable from undatable specimens, we examined the number of rings in the prehistoric and historic Douglas-fir samples. Ring counts for the undated specimens may be slightly inaccurate because of missing or false rings not accounted for in simple ring counts. Because all the samples compared are Douglas-fir, however, ring counts of undated specimens are probably within a few rings of the true number of years on a sample. Therefore, the counts should provide general parameters.

The number of rings on the historic period samples is concentrated into a smaller range (typically between 90-125 rings) than on the prehistoric samples (typically 40-120 rings) (Figure 9). A two-sample t-test of mean ring number shows that this difference is not statistically significant $(\mathrm{t}=0.524$, $\mathrm{df}=20.2, \mathrm{p}=0.606)$. Indeed, 13 prehistoric samples have more than 100 rings, but only six yielded dates; conversely, two historic period samples have more than 200 rings but did not date.

Comparing only the dated and undated prehistoric Douglas-fir samples shows much greater differences (Figure 10). The average number of rings on the dated samples is 104 and the average on undated samples is 60 . Certainly, the dated samples often have more rings, and many undated samples simply have too few rings, but 


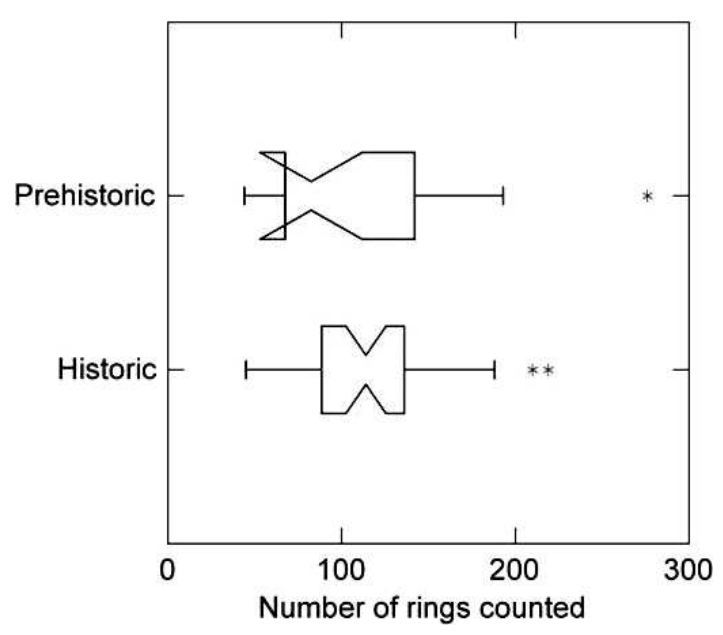

Figure 9. Comparison of the number of rings on prehistoric and historic period Douglas-fir samples showing no significant difference $(\mathrm{t}=0.524, \mathrm{df}=20.2, \mathrm{p}=0.606)$.

the difference is not statistically significant $(\mathrm{t}=$ 2.523, df $=19.7, \mathrm{p}=0.02$ ).

\section{Qualitative Comparisons}

Beam size and number of rings are certainly important factors in the success of archaeological tree-ring dating. Other factors, however, are important as well. Factors such as the spread of date ranges, the number and proportion of cutting dates, and number and proportion of deadwood elements (++ dates) all influence the datability of samples as well.

The spread of dates impacts the analyst's ability to efficiently date samples in two ways. First, if there is a relatively small spread, like that exhibited by the historic period samples (1649-1895), there is simply a much shorter time span to search and the analyst may have more familiarity with the ring sequences because of the presence of other ring attributes such as thick or thin latewood bands, false rings, and resin ducts. In contrast, a wide spread of dates, like that exhibited by the prehistoric samples (609-1126) decreases the ease of finding an exact match with the master skeleton plot or using nonwidth ring features to identify marker rings.

Second, analyst ability to recognize ring sequences is much higher when the outside dates fall in a short span (1848-1895) compared to a much longer span (708-1126). Clusters of cutting

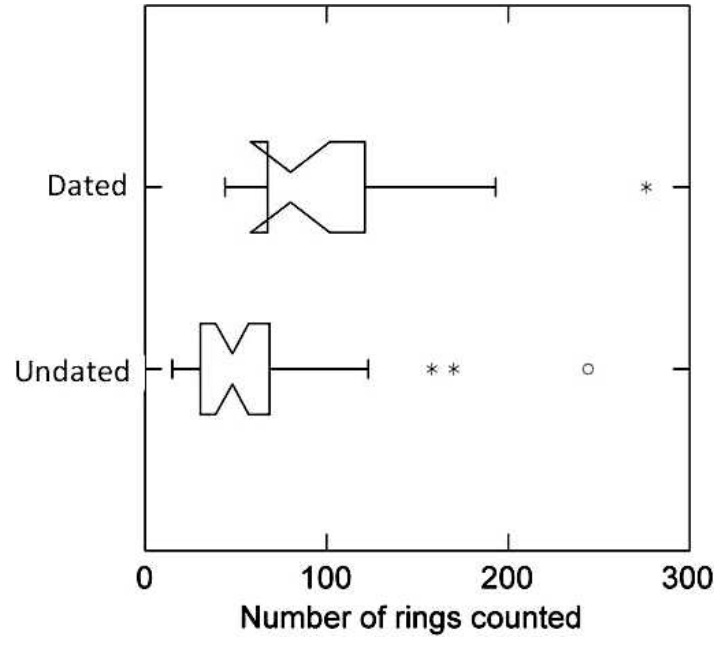

Figure 10. Comparison of number of rings on dated and undated prehistoric Douglas-fir samples showing no significant difference $(\mathrm{t}=2.523, \mathrm{df}=19.7, \mathrm{p}=0.200)$.

dates, supported by noncutting dates and qualitative ring features, do, by definition, reveal very distinctive patterns. If such patterns are in a short time span, it is simply easier to crossdate a specimen.

The use of deadwood may also influence dating success rates. Deadwood is often, but not always, indicated by "++" dates that have locally absent rings and compressed ring series near the outside of the ring sequence (Ahlstrom 1985; Towner 2002). If deadwood use is common, it can be expected that some, or maybe even many, samples will be undatable because the ring series is compressed and/or there are too many locally absent rings for verifiable crossdating.

\section{DISCUSSION AND CONCLUSIONS}

The dendroarchaeological samples from Range Creek in northeastern Utah provide excellent examples of the importance of past human behavior in the success of archaeological tree-ring dating. Despite the fact that the same tree species were available and a single chronology was used in analysis, there are major differences in the number of dates from historic period Anglo homesteads as opposed to dates from Fremont-era structures.

Anglo homesteaders exploited almost exclusively Douglas-fir to build large rectangular log 
cabins. These structures required long, straight timbers - the kind of logs only available as Douglas-fir in the area; none of the other tree species grow as long or as straight. These size requirements also necessitated the use of the boles of trees and precluded using limbs or smaller elements. Finally, the construction of these buildings was accomplished over a very short span of time using freshly cut timbers. Thus, clusters of cutting dates from a "cohort" of living trees with similar ring features made for more efficient crossdating.

The Fremont, on the other hand, built smaller, non-habitation structures that had much less stringent requirements for beam size and shape. They were, therefore, able to exploit a much wider variety of tree species, many of which have growth patterns that cannot be crossdated. Even among the datable species used by the Fremont, these less stringent building requirements allowed them to use smaller elements - probably branches rather than tree boles. They were also able to exploit deadwood to a much greater degree than the Anglo homesteaders. Finally, because the granary dates span more than 500 years, there are no significant date clusters, and qualitative ring features are not as recognizable, crossdating is more difficult and impossible in many cases.

As Dean (1996b:503) states, "Tree-ring dating the archaeological manifestations of past human activities is far more complex than is commonly supposed." Although many factors influence the success rate of archaeological treering dating, by far the most important is the behavior of the people who built and used structures. As shown by the Range Creek data, their decisions concerning the use of various tree species, the size and shape of timbers to harvest, and the use of dead wood elements all have major influences on the dating success rate of dendroarchaeological samples.

\section{ACKNOWLEDGMENTS}

This project was funded in part by the National Science Foundation (BCS-0523995) and National Geographic Society (CRE grant 7859-05). We very much appreciate the help of Jeff Dean, Waldo Wilcox, and those climbers who helped us collect tree-ring samples, namely the Utah County Search and Rescue Team, National Geographic team members/climbers Greg Child, David Roberts and Josh Gross, and Brigham Young University graduate student David Yoder. Field school students from Salt Lake Community College, the College of Eastern Utah, the University of Utah's Andy Yentsch and Joel Boomgarden, and volunteers from the Utah Statewide Archaeological Society helped in numerous ways. Chris Baisan helped develop Range Creek chronologies, and Dave Meko generously provided Harmon Canyon data. We also thank the Bureau of Land Management-Price Field Office and the Utah Division of Wildlife Resources.

\section{REFERENCES CITED}

Ahlstrom, R. V. N., 1985. The Interpretation of Archaeological Tree-Ring Dates. Ph.D. dissertation, The University of Arizona, Tucson. University Microfilms International, Ann Arbor.

, 1997. Sources of variation in the Southwestern archaeological tree-ring record. Kiva 62:321-348.

Barlow, K. R., 2004. Prehistoric food caching strategies: The granaries of Range Creek, Utah. Presented at the $29^{\text {th }}$ Great Basin Anthropological Conference, Sparks, NV, October 14

Dean, J. S., 1996a. Dendrochronology and the study of human behavior. In Tree-Rings, Environment, and Humanity, edited by J. S. Dean, D. M. Meko, and T. W. Swetnam, Radiocarbon, Tucson; pp. 461-469.

, 1996b. Behavioral sources of error in archaeological tree-ring dating: Navajo and Pueblo wood use. In Tree Rings Environment, and Humanity, edited by J. S. Dean, D. M Meko, and T. W. Swetnam, pp. 497-503. Radiocarbon, Tucson

Fritts, H. C., 1976. Tree Rings and Climate. Academic Press, New York.

Gray, S. T., S. T. Jackson, and J. L. Betancourt, 2004. Tree-ring based reconstructions of interannual to decadal scale precipitation variability for northeastern Utah since 1226 A.D. Journal of the American Water Resources Association, Paper No. 03148 (August) 947-960.

Robinson, W. J., B. G. Harrill, and R. L. Warren, 1974. TreeRing Dates from New Mexico B Chaco-Gobernador Area. Laboratory of Tree-Ring Research, The University of Arizona, Tucson.

Schulman, E., 1948. Dendrochronology in northeastern Utah. Tree-ring Bulletin 15:2-14.

Stockton, C. W., J. B. Harsha, and G. Jacoby, 1972. Uinta Mountains Site C. International Tree-ring Data Bank. http:// www.ncdc.noaa.gov/paleo/treering.html. 
Stokes, M. A., and T. L. Smiley, 1968. An Introduction to TreeRing Dating. University of Chicago Press, Chicago.

Stokes, M. A., and T. Harlan, 1965. Nine Mile Canyon (High), Utah. International Tree-Ring Data Bank. http://www.ncdc. noaa.gov/paleo/treering.html.
Towner, R. H., 2002. Archaeological dendrochronology in the US Southwest. Evolutionary Anthropology 11(2):68-84.

Received 26 February 2008; accepted 20 February 2009. 